\title{
A clinical study on the effect of attachable periodontal wound dressing on postoperative pain and healing
}

\author{
Han-Seul Min', Dae-Young Kang1, Sung-Jo Lee ${ }^{1,2}$, Sei-Young Yun³, Jung-Chul Park', In-Woo Cho* \\ ${ }^{1}$ Department of Periodontology, College of Dentistry, Dankook University, Cheonan, Republic of Korea \\ ${ }^{2}$ Department of Periodontology, Dankook University Sejong Dental Hospital, Sejong, Republic of Korea \\ ${ }^{3}$ Department of Cosmetic Science, Daejeon Health Institute of Technology, Daejeon, Republic of Korea
}

\begin{abstract}
Purpose: After periodontal surgery, studies have found that the use of periodontal wound dressing reduces the risk of wound infection and increases healing. The purpose of this study is to evaluate the effect of attachable periodontal wound dressing on the healing and patient satisfaction after periodontal flap surgery. Materials and Methods: Twenty-eight patients requiring periodontal surgery underwent periodontal flap surgery on both quadrants of maxilla or mandible. Postoperative pain, bleeding, dietary discomfort and hypersensitivity in relation to attachable periodontal wound dressing was assessed using Visual Analogue Scale (VAS). Additional survey on frequency of burning sensation and overall satisfaction rates were assessed. Results: VAS mean values for pain, bleeding, and dietary discomfort depending on the presence and absence of attachable wound dressing were; pain: 2.82 , $3.96(P=0.002)$, bleeding: 1.61, $2.54(P=0.008)$, dietary discomfort: $2.82,4.18(P<0.001)$, respectively. Test groups with attachable wound dressing reported significantly lower rates of discomfort. No significant difference was observed in burning sensation and hypersensitivity related with wound dressing. Satisfaction was higher in $75 \%$ of patients who received wound dressing. Conclusion: According to the results of this study, patients who received attachable periodontal wound dressing reported less postoperative pain, bleeding, and dietary discomfort. There was no statistical significance related to the use of wound dressing with burning sensation and hypersensitivity. (J Dent Rehabil Appl Sci 2020;36(1):21-8)
\end{abstract}

Key words: periodontal dressings; wound healing; postoperative care; surgical flap; visual analog scale

\section{서론}

구강내에서 시행되는 수술 후 생긴 창상이나 봉합면은 혀나 음식물 등으로부터 지속적인 자극이 가해질 수 있 다. 이로 인해 치아의 지각 과민이 생기거나 술부의 불편 감이 증가될 수 있다. 또한, 이러한 자극은 봉합사를 풀 리게 만들거나 심한 경우 이차 감염을 발생시켜 치유를 지연시킨다. 이를 방지하기 위해 창상면을 보호하는 치 주포대의 이용이 제안되었다.
치주 포대는 1923년 Ward ${ }^{1}$ 가 처음 소개하였으며, 그는 치주 포대가 치아와 연조직의 움직임을 막아주어 치유에 도움이 된다고 하였다. 이후 다양한 종류의 치주포대들 이 개발되었으며 현재는 두 가지 제형을 혼합하여 사용 하는 페이스트 형태부터 젤형, 부착형 등 다양한 성상의 치주포대가 출시되고 있다.

성상 뿐 아니라 성분에 관한 연구도 활발히 이루어졌 는데, 산화아연유지놀을 함유한 제품이 많았고, $5 \%$ 의 설 파티아졸이나 페니실린을 첨가한 제품 등도 있었다. 그

*Correspondence to: In-Woo Cho

Assistant Professor, Department of Periodontology, College of Dentistry, Dankook University, 119 Dandae-ro, Dongnam-gu, Cheonan, 31116, Republic of Korea

Tel: +82-41-550-1931, Fax: +82-303-3442-7364, E-mail: sinuslift@dent.dku.edu

Received: January 7, 2020/Last Revision: February 21, 2020/Accepted: February

21,2020 
러나 최근 연구에 따르면 포대 안의 성분보다는 포대와 조직간의 긴밀한 표면접촉이 중요한 역할을 하는 것으로 밝혀졌다. ${ }^{2}$

치주 포대의 사용 목적은 수술 후 창상을 보호하여 치 유를 돕는 것이다. 또한 치주 수술 후 발생하는 동통을 감소시키고 수술 부위 치아를 온, 냉 자극으로부터 격리 하여 과민증을 예방함으로써 환자의 불편감을 줄여줄 수 있다. ${ }^{3}$ 그 밖에도, 창상에 세균성 침착물의 저류를 방지 하여 이차 감염을 막을 수 있도록 하며, ${ }^{4}$ 창상의 초기 고 정을 돕는다. ${ }^{5}$

반면 치주 포대의 사용과 관련하여 회의적인 연구 결 과들도 있다. Bae 등과 Checchi 등은 수술 후 동통 과 치주포대의 적용 유무는 연관이 없다고 보고하였다. Greensmith ${ }^{8}$ 는 포대를 사용할 경우 오히려 더 심한 종창 과 동통이 발생한다고 보고하였고, 또 다른 연구에서 이 러한 치유 지연과 불편감의 원인으로 포대의 장기간 유 지로 인한 수술부위의 과도한 치태 침착 가능성이 제기 되었다. ${ }^{9}$

치주 포대의 부착기간과 관련하여 Orban 등 ${ }^{5}$ 은 치주 포대의 사용이 12 일을 초과할 경우 치유를 지연시킨다고 하였고, 가능하다면 2 - 4일 간격으로 포대를 교체해줄 것을 권하고 있다.

최근 개발된 부착형 창상 피복재의 경우 별도의 혼합 과정 없이 쉽게 원하는 모양으로 다듬어 환부에 적용할 수 있다. 또한, 부착 후 6-12시간 정도 유지되다가 자연 탈락하므로 발사 전에 피복재를 제거하기 위해 별도로 병원을 재내원하지 않아도 되며, 장기간 부착된 피복재 로 인한 치태축적이 치유를 방해할 가능성이 낮기 때문 에 기존의 치주포대에서 처럼 종창 및 통증을 유발할 위 험이 없다.

본 연구에서는 치주판막 수술 후 부착형 창상 피복재 의 적용 유무에 따라 환자가 느끼는 술 후 불편감과 환자 의 수술 만족도에 대해 조사하고자 한다.

\section{연구 재료 및 방법}

본 연구는 D기관 윤리심의위원회(Institutional Review Board, [IRB])의 승인(IRB No. DKUDH IRB 2018-06002)을 얻은 후 2018년 9월부터 2019년 3월까지 진행되 었다. 실험은 ○○대학교 치과병원 치주과에 내원하는 중 등도 만성치주염 환자 중 상악 또는 하악의 2 사분악 이 상에서 치은박리소파술이 예정되어 있는 자 가운데, 자
발적으로 본 임상연구에 참여하기로 동의한 환자를 대상 으로 하였다. 표본의 크기와 관련하여 유의수준 0.05 에서 VAS 0.5 점 차이를 유효크기로 하여 $75 \%$ 의 검정력을 갖 기 위한 표본 수는 23 명이며, 중도 탈락율을 $20 \%$ 로 설정 하고 총 28 명의 환자를 모집하였다.

연구 대상자의 선정 기준은 다음과 같다;

- 만 20세 이상 65세 미만

- 중등도(probing pocket depth $\geq 5 \mathrm{~mm}$, 비외과적 치 주치료를 종결한 경우) 만성치주염 환자

- 2 사분악 이상에서 치은박리소파술이 예정되어 있는 자 또한, 제외 기준은 다음과 같다;

- 최근 3개월 이내 항생제, 스테로이드를 복용한자

- 조절되지 않는 당뇨 환자

- 급진성 치주염 환자

- 기타 창상 치유를 저해하는 전신병력이 있는 자(면역 억제제 복용 중인 자, 면역질환자)

본 연구에 사용된 부착형 창상 피복재는 Ora-Aid (TBM, Gwangju, Korea)로 에틸셀룰로오스와 폴리에틸 렌테레프탈레이트를 주성분으로 하는 고분자화합물로 토코페롤아세테이트와 포비돈, 카보머 등의 유효성분을 포함하여 창상치유, 지혈효과를 가진다.

부착형 창상 피복재는 두 가지 크기 $(50 \mathrm{~mm} \times 20 \mathrm{~mm}$ 또는 $25 \mathrm{~mm} \times 15 \mathrm{~mm}$ )로 제공되며 치주 수술 봉합 후 원하는 크기로 다듬어, 수술 부위에 적용한다. 이후 평균 6 - 12시간 부착 상태를 유지하다가 탈락하므로 별도의 제거를 위한 내원이 필요하지 않다.

창상과 접촉하는 접착면은 점막부착성 고분자로 단시 간 내에 구강내의 수분과 반응하여 겔 상태로 변화하고 이후 점착성이 발생하여 점막에 부착된다. 보호면의 고 분자는 불수용성으로 창상을 덮어 구강내의 환경(타액, 음식물 등)으로부터 환부를 보호한다(Fig. 1).

실험에 참여한 환자들은 처음 내원 시 임상연구에 관 한 설명동의서 작성과 무작위 그룹 배정을 시행하였고, 총 4주에 걸쳐 두 분악에 치주 판막수술을 시행하였으며, 자세한 수술 일정은 Table 1 과 같다.

2사분악 이상의 치주치료가 예정된 환자를 대상으로 상악 좌·우측 또는 하악 좌·우측을 split mouth design하 여, 양쪽 모두 치은박리소파술을 시행하며 두 번의 수술 중 한번은 부착형 창상 피복재를 적용하고 다른 한번은 적용하지 않았다. 모든 환자에서 수술은 좌측에서 우측 순서로 진행되었다. 피험자를 $\mathrm{A}$ 와 $\mathrm{B}$ 가 적힌 종이를 이용 


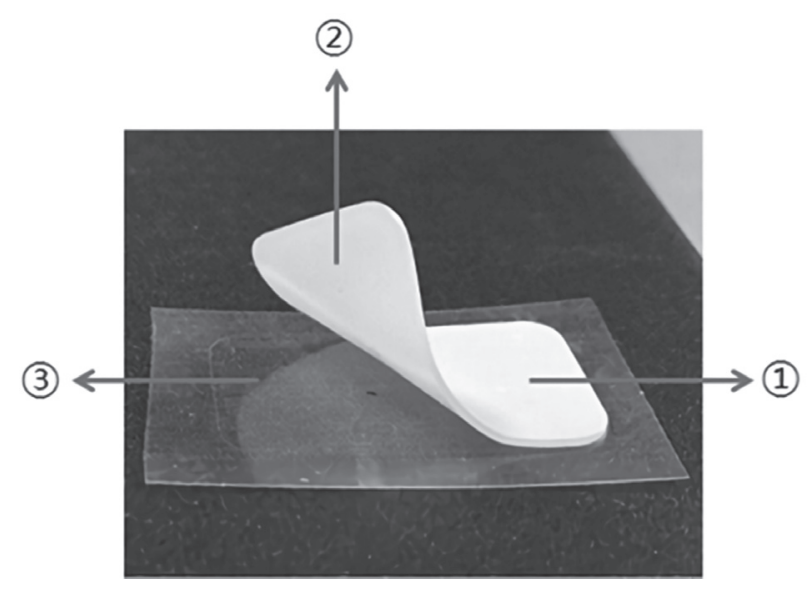

Fig. 1. Ora-Aid (1) protective surface. Protect the adhesive surface. (2) Adhesive side. When it meets saliva, it has adhesive properties and protects the wound site from the outside. (3) Peeling surface. As a layer to protect the adhesive surface, When applying wound dressing it removed and used.

Table 1. Surgical procedures

\begin{tabular}{ll}
\hline \multicolumn{3}{c}{ Split mouth design으로 사분악 중 양측 flap surgery 시행 } \\
\hline Day 0 & 수술 및 설명동의서 작성 \\
무작위 배정을 통한 부착형 창상피복재 적용 부위 결정 \\
Day 11 & 첫 수술 부위 수술 시행(Open flap debridement) \\
Day 14 & 첫 수술 부위 발사 진행 \\
& 설문을 통하여 다음 항목 조사 \\
& 1) VAS \\
& - 술 후 통증, 출혈, 식이 불편감, 지각과민 \\
2) 사지선다 & - 작열감 \\
두 번째 수술 부위 수술 진행 \\
두 번째 수술 부위 발사 진행 \\
설문을 통하여 다음 항목 조사 \\
1) VAS \\
- 술 후 통증, 출혈, 식이 불편감, 지각과민 \\
2) 사지선다 \\
- 작열감 \\
3) 이분형 변수 \\
- 수술 만족도 조사
\end{tabular}

하여 무작위로 두 그룹으로 배정하였다. A 그룹은 두 번 의 예정된 수술 중 첫 번째 수술 시 부착형 창상 피복재를 적용하고, 두 번째 수술 시에는 적용하지 않았다. 이와 반 대로 $\mathrm{B}$ 그룹은 첫 번째 수술 시에 부착형 창상 피복재를 적용하지 않고, 두 번째 수술 시에 부착형 창상 피복재를 적용하였다(Fig. 2).

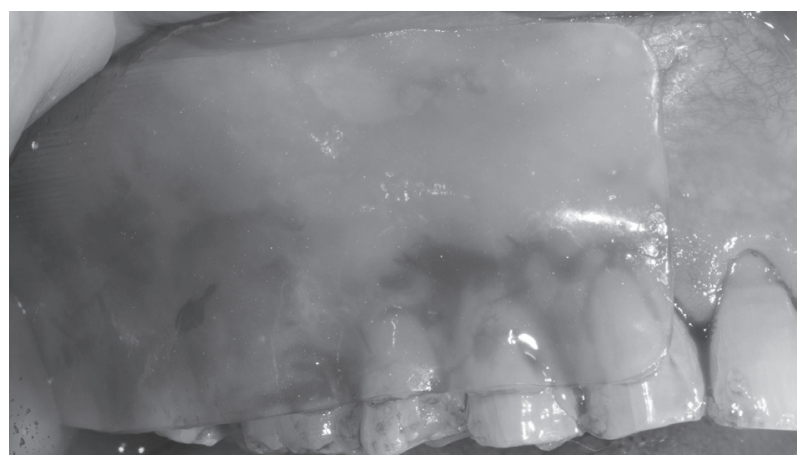

Fig. 2. Clinical photo of attachable wound dressing after periodontal flap surgery.

수술 후 설문 조사를 통해 수술 후 동통, 출혈, 식이 불 편감 및 작열감, 지각 과민에 대해 조사하였다. 동통, 출 혈, 식이 불편감, 지각 과민은 Visual Analog Scale (VAS) 를 사용하여 ‘ 0 (불편감 없음)’에서 ‘ 10 (최악의 상상할 수 있는 불편감)'까지로 평가하였고, 작열감은 4 개의 사지선 다(0회, 1 - 3회, 4 - 10회, 10 회 이상), 만족도는 이분형 변 수(적용부위, 비적용부위)로 평가하였다.

Wilcoxon singed rank test를 사용하여 부착형 창상 피 복재의 유무에 따른 술 후 불편감의 통계적 유의성을 분 석하였다. 통계 분석은 SPSS 소프트웨어 version 18.0 (IBM, Armonk, USA)를 사용하였다.

\section{결과}

총 28 명의 환자가 연구에 포함되었으며 중도 탈락된 경우는 없었다. 환자의 평균 $( \pm \mathrm{SD})$ 연령은 55.46 (⒏56) 세였으며, 전체 $42.8 \%$ 가 여성이었다. 부착형 창상 피복 재를 적용한 경우(실험군) 28 번의 수술에서 평균 술 후 동통 점수는 $2.82( \pm 2.14)$ 이다. 이에 반해, 부착형 창상 피복재를 사용하지 않은 경우(대조군)에서 술 후 동통 점 수는 $3.96( \pm 2.72)$ 으로 두 군간의 동통 차이는 통계적으 로 유의하였으며, 실험군에서 적었다 $(P=0.002)$. 또한, 출혈로 인한 불편감에 대한 점수는 실험군과 대조군에서 각각 1.61 ( \pm 1.85$), 2.54$ ( \pm 2.52$)$ 로 부착형 창상 피복재 를 적용한 그룹에서 적었으며, 통계적으로 유의하였다 $(P$ $=0.008)$. 수술 후 식이 섭취의 불편감에 관한 설문에서 실험군의 평균은 2.82 ( \pm 2.23$)$ 였으며, 대조군의 평균은 4.18 ( \pm 3.02 )였다. 부착형 창상 피복재를 적용한 경우가 통계적으로 유의하게 식이 불편감이 적었다 $(P<0.001)$. 
Table 2. Severity of discomfort (VAS score) in surgical sites with and without attachable periodontal wound dressing

\begin{tabular}{|c|c|c|c|c|c|c|}
\hline \multirow[t]{2}{*}{ Discomfort } & \multirow{2}{*}{$\begin{array}{l}\text { Use of attachable } \\
\text { periodontal } \\
\text { wound dressing }\end{array}$} & \multicolumn{4}{|c|}{$\begin{array}{l}\text { Severity of discomfort } \\
\text { (VAS discomfort score out of } 10 \text { ) }\end{array}$} & \multirow[t]{2}{*}{$P$ value } \\
\hline & & Mean & $\mathrm{SD}$ & Minimum & Maximum & \\
\hline \multirow{2}{*}{ Pain } & Yes & 2.82 & 2.72 & 0 & 8 & \multirow{2}{*}{$0.002^{*}$} \\
\hline & No & 3.96 & 2.14 & 0 & 10 & \\
\hline \multirow{2}{*}{ Bleeding } & Yes & 1.61 & 1.85 & 0 & 8 & \multirow{2}{*}{$0.008^{*}$} \\
\hline & No & 2.54 & 2.52 & 0 & 8 & \\
\hline \multirow{2}{*}{ Intake } & Yes & 2.82 & 2.23 & 0 & 8 & \multirow{2}{*}{$<0.001^{*}$} \\
\hline & No & 4.18 & 3.02 & 0 & 10 & \\
\hline \multirow{2}{*}{ Hyper-sensitivity } & Yes & 1.96 & 2.24 & 0 & 8 & \multirow{2}{*}{0.074} \\
\hline & No & 2.54 & 2.66 & 0 & 8 & \\
\hline
\end{tabular}

* Significantly different $(P<0.05)$.

SD: standard deviation, Vas: visual analogue scale.

이에 반해, 수술 후 지각 과민으로 인한 불편감에 대한 점 수는 부착형 창상 피복재의 적용 유무에 따라 각각 1.96 ( \pm 2.24), 2.54 ( \pm 2.66$)$ 로 나타났으며, 통계적으로 유의 한 차이가 관찰되지 않았다 $(P=0.074$, Table 2$)$.

사지선다를 이용하여 조사한 작열감으로 인한 불편감 에서는 실험군과 대조군 간의 차이가 크지 않았다. 작열 감 평가에서 10 회 이상의 불편감을 느낀 사람은 대조군 에서 2 명이었으며, 실험군에서는 1 명으로 상대적으로 적 었으며, 불편감을 느끼지 못했다고 응답한 사람의 수도 대조군 18 명, 실험군 19 명으로 실험군에서 더 많았으나, 두 군간의 통계적으로 유의미한 차이는 없었다(Table 3).

Split mouth로 두 번의 수술을 경험하면서 한쪽은 창 상피복재를 부착하고 다른 한쪽은 부착하지 않았던 실 험 대상자들에게 각각의 수술부위에 대한 만족도를 조 사하였을 때 $75 \%$ (21명)의 환자가 부착형 창상 피복재를 적용한 수술부위를 선택하였고, $18 \%$ (5명)의 환자가 양 수술부위의 수술만족도 차이가 없다고 응답했다. 부착형 창상 피복재를 적용하지 않은 수술이 더 만족스럽다는 대답은 전체 환자 중 7\% (2명)였다(Fig. 3).

\section{고찰}

$\mathrm{Baer}^{10}$ 는 치주 포대 사용의 목적을 환자의 동통과 불 편감 감소 그리고 치유기간 동안에 추가적인 손상을 방 지하여 창상의 초기치유가 원활하게 이루어질 수 있도록 하는 것이라 하였다. 치주 포대 부착 시 동통이 감소하는
Table 3. Burning discomfort

\begin{tabular}{ccc}
\hline $\begin{array}{c}\text { Use of attachable } \\
\text { periodontal wound dressing }\end{array}$ & Yes & No \\
\hline 0 & 19 & 18 \\
$1-3$ times & 6 & 7 \\
$4-10$ times & 2 & 1 \\
$\geq 10$ times & 1 & 2 \\
Total & 28 & 28 \\
\hline
\end{tabular}

Patient Satisfaction

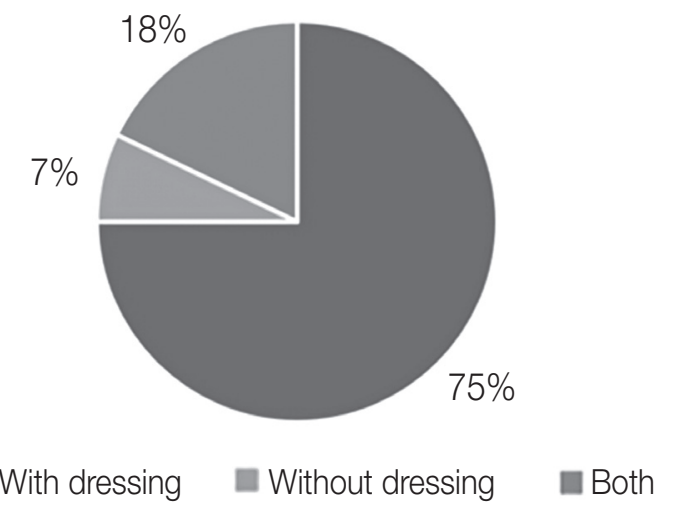

Fig. 3. Surgical Site Satisfaction Survey. $75 \%$ of the subjects selected surgical sites using attachable wound dressing. 
이유는 포대가 창상 부위를 고정하여 혈병 안정화를 돕 고, 물리적인 자극으로부터 환부를 보호하기 때문이다. 본 실험결과에서도 부착형 창상 피복재의 사용 유무와 동통, 출혈, 식이 불편감 간에 통계적으로 유의미한 차이 가 있었으며, 부착형 창상 피복재를 적용한 경우 불편감 이 적었다.

화끈거리는 통증으로 인한 불편감에 관해서는 부착 형 창상 피복재를 부착한 실험군에서 평균값이 좀 더 작 았으나 통계적으로 유의한 차이는 없었다. 작열감의 경 우 창상의 일차 피개(primary closure)가 되지 않는 경 우 증가하는데, ${ }^{11}$ 본 실험에서 시행한 치주판막수술은 open flap debridement 형태로 모든 부위에서 일차 피개 (primary closure)가 이루어지므로 대조군과 실험군 간에 통계적으로 유의한 차이가 없었던 것으로 생각된다.

VAS는 통증의 정도 측정에 가장 일반적으로 사용되 는 방법 중 하나로, 통증 뿐만 아니라 다른 심리 현상(우 울증, 불안신경증 등)이나 증상의 정도(오심, 피로, 호흡 곤란 등), 기능이나 삶의 질 등을 측정하는 데에도 폭 넓 게 이용되고 있다. ${ }^{12} \mathrm{VAS}$ 는 다양한 환경에서 쉽게 사용이 가능할 뿐 아니라 측정자가 사용하기 전 방법을 숙지하 기 위해 필요한 연습시간이 적다. 또한, 측정된 자료는 통 계처리가 가능하다. ${ }^{13}$ 그 밖에 VAS는 회상을 통해 최근 에 느꼈던 통증에 대한 평가가 가능하다는 점 때문에 본 실험에서는 split mouth design에서 통증을 평가하는데 가장 적절하다고 생각되어 VAS 방식을 선택하여 설문을 진행하였다. ${ }^{14}$

동통이나 불편감이라는 검사 항목은 환자에 따라 상 당히 주관적인 성질의 자료로써 개개인의 복잡한 경험과 심리상태를 반영한다. 이를 잘 평가하기 위해 본 실험에 서 설계한 split mouth design의 경우 동일한 대상의 서로 다른 부분에 같은 술식을 적용 후 한 쪽은 부착형 창상 피복재를 적용하고 다른 한쪽은 적용하지 않음으로써 적 은 수의 표본 집단이라도 개인의 특성에 따른 영향을 줄 여주어 치료효과를 보다 정확하게 평가할 수 있다. ${ }^{15}$

본 연구에서 사용한 부착형 창상 피복재(Ora-Aid)의 경우 부착 스트립형으로 기존 페이스트 형태의 제품에 비해 조작이 간편하고 부착이 쉽다. 또한 페이스트 형태 의 치주포대를 구강내 적용한 경우 이물감 때문에 불편 감을 호소하는 환자들이 많은 반면 부착형 창상 피복재 는 두께가 얇아 이물감이 낮다. Heaney ${ }^{16}$ 에 따르면 치주 포대를 사용한 경우 포대 자체가 조직에 해를 끼치는 것 은 아니나 사용하지 않은 부위보다 염증이 더 심한 경우
가 있다고 하였는데, 이는 포대가 치태침착을 유발하여 치유 중인 조직에 자극을 가한 결과로 생각된다. 또한 동 일한 연구에서 치태침착이 치유에 영향을 미치는 것을 막 기 위해 수술 후 1 주일 내에 포대를 제거해야 한다고 말 했다. 이러한 점에서 부착형 창상 피복재의 경우 타액과 접촉 시 겔화되어 접착력이 발생하고 평균 6 - 12시간 지 속 후 접착면이 분해되어 자연 탈락하여 환자 스스로 제 거가 가능하다. 따라서 피복재 제거를 위한 재내원이 필 요하지 않으며 치태침착으로 인한 불량한 치유에 대한 우려가 적다.

본 연구에서는 치주수술 후 동통과 불편감에 영향을 주는 요인으로 부착형 창상 피복재의 사용 유무를 설정 하였지만, 포대 사용 유무 외에 영향을 줄 수 있는 요소 들이 있다. 기본적으로 동통과 불편감의 정도는 포대 사 용유무보다 수술의 정교함과 수술 시간 등에 민감하며, 그 외 영향을 주는 요소로는 골 수술 여부, 의원성 외상의 양 등이 있다. 또한 이러한 요소들은 동통과 불편감 뿐 아니라 치유과정에 전반적으로 영향을 주게 된다. ${ }^{17}$

치주판막수술 외에 부착형 창상 피복재의 적용이 가능 한 부위는 근단변위판막술, 발치와, 치은절제술, 구강내 창상, 구내염 등이 있다. 특히 유리치은이식술 시 구개부 공여부의 경우 대구개동맥의 부가지가 손상되어 출혈로 인한 불편감이 발생하거나 일차피개 없이 노출된 탈상 피화 부위의 통증을 호소하는 경우가 많다. 유리치은이 식술 공여부에 부착형 창상 피복재를 적용한 경우 두께 가 얇아 구개부에 부착하여도 이물감이 크지 않으며, 공 여부 주변 건전한 치은에 견고하게 부착되어 내부에 혈 병을 가두어 지혈을 돕는다. 또한 노출된 창상을 피개하 여 혀나 음식물에 의한 자극을 막고 감염을 방지하여 초 기치유를 돕는다. 실제 임상에서 지혈을 위한 별도의 공 여부 봉합없이 부착형 창상 피복재의 사용만으로 충분한 지혈효과와 치유결과를 얻었다(Fig. 4).

\section{결론}

부착형 창상 피복재의 치주판막수술 후 사용유무에 대 해 술 후 발생되는 동통이나 불편감의 정도와 선호도 등 을 조사하기 위해 ○○대학교 치과대학 부속 치과병원치 주과에 내원한 환자 28 명을 대상으로 설문한 결과 다음 과 같은 결론을 얻었다.

1. 술 후 동통, 출혈, 식이 불편감의 정도는 부착형 창상 피복재 적용 군이 적용하지 않은 군에 비하여 통계 

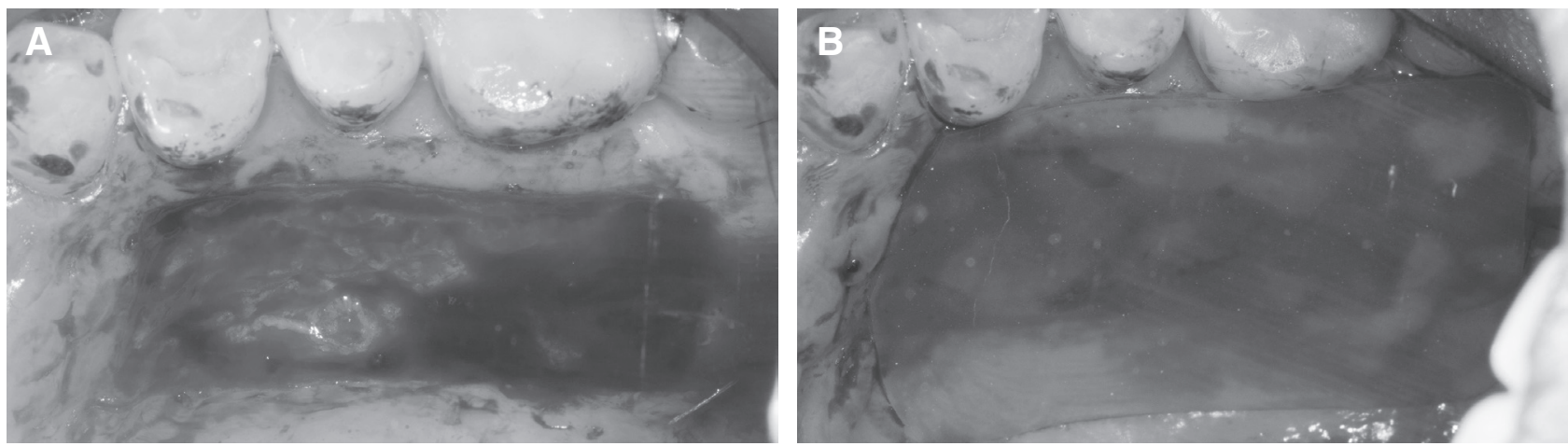

Fig. 4. Attachable wound dressing was applied to the palatal donor site for free gingival graft and hemostasis were performed without additional suture.

적으로 유의하게 불편감이 적었다.

2. 술 후 발생하는 작열감, 지각 과민에 대한 분석에서 부착형 창상 피복재 사용 여부에 따른 두 군간에 통 계적으로 유의한 차이가 없었다.

3. 수술에 대한 환자 만족도 검사에서 $75 \%$ 의 환자가 부착형 창상 피복재를 적용한 수술부위를 선택하였 고, $18 \%$ 가 별다른 차이가 없었다고 하였으며, $7 \%$ 가 부착하지 않은 경우를 선택하여 창상 피복재의 사용 을 원치 않았다.

이상의 결과로 치주판막수술 후 동통과 출혈, 식이 불 편감 감소를 목적으로 부착형 창상 피복재의 사용은 권 유되나, 향후 부착시간 조절이나 부착력, 형태 등에 대한 추가적인 연구가 필요할 것으로 사료된다.

\section{ORCID}

Han-Seul Min https://orcid.org/0000-0003-1658-2001

Dae-Young Kang https://orcid.org/0000-0002-4311-4118

Sung-Jo Lee https://orcid.org/0000-0002-7834-209X

Seiyoung Yun https://orcid.org/0000-0002-5542-069X

Jung-Chul Park https://orcid.org/0000-0002-2041-8047

In-Woo Cho https://orcid.org/0000-0003-4985-3816

\section{References}

1. Ward A. Inharmonious cusp relation as a factor in periodontoclasia. J Am Dent Assoc 1923;10:47181.

2. Linghorne WJ, O'Connell DC. The therapeutic properties of periodontal cement pack. J Can Dent Assoc 1949;15:199-205.

3. Mann JB, Crane AB, Kaplan H. Pyorrhea alveolus: histopathology and results of radical surgical treatment. Dent Cosmos 1934;76:432.

4. Ward AW. Postoperative care in the surgical treatment of pyorrhea. J Am Dent Assoc 1929;16:63540.

5. Orban B. Indications, technique and postoperative management of gingivectomy in the treatment of the periodontal pocket. J Am Dent Assoc 1941;12: 89-95.

6. Bae SB, Lim SB, Chung CH. A Comparative study of clinical effects following periodontal surgery with and without dressing. J Korean Acad Periodontol 1999;29:693-701.

7. Checchi L, Trombelli L. Postoperative pain and discomfort with and without periodontal dressing in conjunction with $0.2 \%$ chlorhexidine mouthwash after apically positioned flap procedure. J Periodontol 1993;64:1238-42.

8. Greensmith AL, Wade AB. Dressing after reverse bevel flap procederes. J Clin Periodontol 1974;1:97106.

9. Stahl SS, Witkin GJ, Heller A, Brown R Jr. Gingival healing. III. The effects of periodontal dressing on gingivectomy repair. J Periodontol 1969;40:34-37.

10. Baer PN, Sumner CF 3rd, Miller G. Periodontal dressings. Dent Clin North Am 1969;13:181-91.

11. Greenstein G, Greenstein B, Cavallaro J, Elian N, Tarnow D. Flap advancement: practical techniques 
to attain tension-free primary closure. J Periodontol 2009;80:4-15.

12. Miller MD, Ferris DG. Measurement of subjective phenomena in primary care research: the visual analogue scale. Fam Pract Res J 1993;13:15-24.

13. Philip BK. Parametric statistics for evaluation of the visual analog scale. Anesth Analg 1990;71:710.

14. Singer AJ, Kowalska A, Thode HC Jr. Ability of patients to accurately recall the severity of acute painful events. Acad Emerg Med 2001;8:292-5.

15. Checchi L, Trombelli L. Postoperative pain and discomfort with and without periodontal dressing in conjunction with $0.2 \%$ chlorhexidine mouthwash after apically positioned flap procedure. J Periodontol 1993;64:1238-42.

16. Heaney TG, Appleton J. The effect of periodontal dressings on the healthy periodontium. J Clin Periodontol 1976;3:66-76.

17. Sachs HA, Farnoush A, Checchi L, Joseph CE. Current status of periodontal dressings. J Periodontol 1984;55:689-96. 


\section{부착형 치주 창상 피복재가 치주수술 후 동통 및 치유에 미치는 효과에 관한 임상 연구}

민한슬 ${ }^{1}$ 전공의, 강대영 ${ }^{1}$ 임상연구조교수, 이성조 ${ }^{1,2}$ 임상연구조교수, 윤세영 ${ }^{3}$ 조교수, 박정철 ${ }^{1}$ 조교수, 조인우 ${ }^{*}$ 조교수

${ }^{1}$ 단국대학교 치과대학 치주과학교실

${ }^{2}$ 단국대학교 세종치과병원

${ }^{3}$ 대전보건대학 화장품과학과

목적: 치주포대는 감염 위험을 줄이고 치유를 증대 시킨다는 연구들이 있다. 본 연구는 치주 수술 후 부착형 창상 피복재 의 사용이 치유 및 수술 만족도에 미치는 영향을 평가하고자 하였다.

연구 재료 및 방법: 치주 수술이 필요한 환자 28명을 대상으로 상악 또는 하악의 양측 사분면에 치주 수술을 시행하였다. Visual Analogue Scale (VAS)를 이용해 술 후 동통, 출혈, 식이 불편감, 지각 과민을 평가하고 추가적으로 작열감과 수술 만족도에 관해 평가하였다.

결과: 수술 후 동통, 출혈, 식이 불편감에 관한 VAS 평균 값은 창상 피복재 유무에 따라 각각; 동통: $2.82,3.96(P=$ $0.002)$, 출혈: $1.61,2.54$ ( $P=0.008)$, 식이 불편감: $2.82,4.18$ ( $P<0.001)$ 로 창상 피복재를 적용한 그룹에서 불편감이 적 었으며, 통계적으로 유의하였다. 작열감, 지각 과민과 창상 피복재 적용 유무 사이에 유의한 차이는 없었다. 수술 만족도 는 $75 \%$ 에서 창상 피복재를 사용한 경우 높았다.

결론: 본 연구의 결과에 따르면, 창상 피복재의 사용유무와 작열감, 지각 과민과의 통계적 유의성은 없었으나 창상 피복 재를 사용한 경우 술 후 동통, 출혈, 식이 불편감이 적었다.

(구강회복응용과학지 2020;36(1):21-8)

주요어: 치주포대; 창상치유; 술 후 처치; 치주 판막 수술; 시각적 아날로그 스케일

*교신저자: 조인우

(31116) 충남 천안시 동남구 단대로 119 단국대학교 치과대학교 치주과학교실

Tel: 041-550-1931 | Fax: 0303-3442-7364 | E-mail: sinuslift@dent. dku. edu

접수일: 2020년 1월 7일 | 수정일: 2020년 2월 21일 | 채택일: 2020년 2월 21일 